\title{
The Boston Circulatory Arrest Study: An analysis
}

Ross M. Ungerleider, MD ${ }^{a, b}$

J. William Gaynor, MD ${ }^{\mathrm{c}}$

See related articles in $J$ Thorac Cardiovasc Surg. 2003;126:138596 and 2003;126:1397-403.
From the Division of Cardiothoracic Surgery, Oregon Health \& Science University, ${ }^{\text {a }}$ Portland, Ore, Department of Pediatric Cardiac Surgery, Doernbecher Children's Hospital,' Portland, Ore, and Children's Hospital of Philadelphia, ${ }^{\mathrm{c}}$ Philadelphia, $\mathrm{Pa}$.

Received for publication Dec 22, 2003; revisions received Dec 31, 2003; accepted for publication Jan 27, 2004.

Address for reprints: Ross M. Ungerleider, MD, Doernbecher Children's Hospital, Pediatric Cardiac Surgery Section, Oregon Health Science University, 3181 SW Sam Jackson Park Rd, DC8S, Portland, OR 97201-3098 (E-mail: ungerlei@ohsu.edu).

J Thorac Cardiovasc Surg 2004;127:1256-61

$0022-5223 / \$ 30.00$

Copyright () 2004 by The American Association for Thoracic Surgery

doi:10.1016/j.jtcvs.2003.12.037

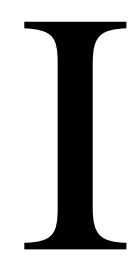

$\mathrm{n}$ their two articles published in the November issue of the Journal, ${ }^{1,2}$ the group from the Children's Hospital in Boston have provided us with the best clinical data available comparing deep hypothermic circulatory arrest (DHCA) with hypothermic, continuous low-flow bypass (LF) - 2 cardiopulmonary bypass (CPB) strategies that are commonly used during the repair of congenital heart defects in infants.

It is relevant to provide a brief historical perspective regarding how and why these studies were designed. DHCA became popular after its use was reported by Kirklin and associates ${ }^{3}$ in 1961 and later in neonates and infants by Barratt-Boyes and associates in $1970^{4}$ because it greatly simplified cardiac repair in infants in an era that did not have the sophisticated CPB technology (including thin-walled cannulas with excellent flow characteristics, smaller circuits with membrane oxygenators, and much more) that we enjoy today. By using DHCA, surgeons could repair intracardiac defects in a bloodless field unencumbered by cannulas. Furthermore, surgeons avoided many of the complications created by the more primitive $\mathrm{CPB}$ systems, and this most likely produced success in an era when prolonged exposure to CPB was very likely detrimental. Results were generally favorable, and the use of DHCA made cardiac repair in infants reproducibly possible. As technology improved and surgeons began to tackle repair of more complex lesions, DHCA became a staple in the armamentarium of cardiac surgeons. Its use became so ingrained in the practice patterns of cardiac surgeons that it was unusual in the 1980s to find successful pediatric cardiac centers anywhere in the world that did not use DHCA on a routine basis.

By the late 1980s, the seeds of concern were germinating regarding the effect of DHCA on the neurologic development of the infants exposed to it. This marked a subtle, but substantial, shift in cardiac surgery for infants-the field was beginning to focus on long-term quality of life rather than just on initial survival. Compared with mortality rates in the earlier days of surgery for congenital heart disease, which were high, mortality after infant heart surgery was becoming less frequent, and rates were comparable with those experienced for adults having more routine procedures (such as coronary artery bypass grafting) - all despite the increasing complexity of defects being repaired by congenital heart surgeons. It was an important era because it heralded the development of so many techniques that we consider commensurate with modern infant heart surgery. Surgeons were shifting to primary repair versus palliation of repairable defects because systems allowed this with predictable survival. Membrane oxygenators; improved methods of myocardial protection; more finely engineered surgical instruments, cannulas, and sutures; and improved prosthetic materials, along with numerous other advances in technology and surgical experience, were enabling surgeons to rethink the systems and techniques that their infant patients were exposed to during surgical reconstruction.

Understanding of the "safe" period of DHCA was still evolving. In general, it was considered acceptable to expose infants to circulatory arrest for as long as 45 to 60 minutes at $18^{\circ} \mathrm{C} .^{5}$ Reports appeared in the literature that attempted to characterize the effect of DHCA on neurodevelopmental outcome. ${ }^{6-9}$ For the most part, these reports were retrospective, noncontrolled reviews of neurologic outcomes for widely dissimilar patients, and they generated increasing concern that DHCA might be associated with movement disorders such as choreoathetosis and with generalized poor neurodevelopmental outcomes. ${ }^{10-17}$ Against the backdrop of these 
retrospective clinical reviews, a few studies were being performed to elucidate the nature of physiologic alterations that occurred within the brain after DHCA, ${ }^{18-44}$ and these studies led to important changes in the application of DHCA that have today changed the expectations from DHCA.

It was during this time that the group at Children's Hospital in Boston was experiencing internationally recognized success with neonatal arterial switch for transposition of the great arteries. They had the great fortune of receiving a large cohort of infants who had the same defect, and fortunately, they had the foresight to randomize these patients into 2 general groups-those who had repair performed with the use of a prolonged period of DHCA and those whose repair was performed with the use of predominately continuous LF ("LF" in the 8-year follow-up study and "E" in the duration study). ${ }^{1,2}$ DHCA was used only briefly during closure of atrial and (when present) ventricular septal defects. These two recently published companion articles $^{1,2}$ have granted us a unique opportunity to examine the outcome for those patients 8 years after their enrollment in this study, and the results provide important insight into what might be expected from a neurobehavioral standpoint in patients who undergo either of these 2 strategies.

Despite the anxiety that has developed in more recent years about the use of DHCA and the enthusiasm expressed by some groups that DHCA should be avoided in favor of continuous low-flow perfusion, ${ }^{45,46}$ the neurologic testing performed at a mean of 8 years after exposure to these 2 CPB strategies failed to show a significant difference between groups. ${ }^{2}$ Each group has its own behavioral signature, which suggests a subtle difference between the effect of strategies that predominantly use DHCA and those that primarily use LF, but it is important to note that the treatment groups did not significantly differ in full-scale IQ, performance IQ, memory screening index, Wechsler Individual Achievement Test summary scores or subscales, the Wisconsin Card Sorting test, visual-spatial or visual-motor skills (although the cohort as a whole was in the 25th percentile), or the proportion of children judged to have a possible or a definite abnormality (however, the frequency of abnormalities was high in both groups compared with the normal population). The DHCA group fared worse than the LF group in areas such as manual dexterity (with the nondominant hand), speech, visual-motor tracking, and phonologic awareness (a skill considered important for the development of reading skills). The LF group was significantly more impaired in measurements of attention and behavior (as graded by teachers). However, the data, when considered for both groups, demonstrate that regardless of the CPB strategy used, both groups were impaired compared with healthy subjects, but neither was more impaired than the other.
The companion article on the effects of duration of DHCA $^{1}$ suggests that if the patients with DHCA times longer than 41 minutes were removed from the total DHCA group, the neurodevelopmental effects would be even less pronounced. Neurodevelopmental outcomes were generally not adversely affected unless the duration of DHCA exceed a threshold of 41 minutes. By comparing groups with a model that analyzed outcome data for various cut points, the authors found no association between duration of DHCA and outcome if the DHCA time was less than 41 minutes. If the duration of DHCA exceeded 41 minutes, there was a significant association between duration of DHCA and outcome in 5 areas: full-scale IQ, verbal IQ, performance IQ, grooved pegboard (a test of motor skills), and the Mayo test of apraxia. They also pointed out the important feature that these findings were produced by application of DHCA in an era (1988-1992) when the typical strategy used exposure to alpha-stat cooling, hemodilution to hematocrits of $20 \%$, outmoded hardware, and no arterial filters, thus implying that outcomes might be different in a more modern era.

How should practitioners interpret the data from these studies? How should these studies influence our practice in 2004, and can we come to any conclusion regarding whether or not DHCA should be used in a modern era?

First, it should be recognized that most children in the Boston review performed well within the normal range. This is hopeful, especially in light of the improvements that have been made in our strategies since this study was designed. It is comforting to know that our selection of CPB repair strategy in the early 1990s did not create significant neurologic issues for survivors compared with the various commonly used strategies that were available to us.

However, before we ignore the findings of these studies as inconclusive, we should pay careful attention to the fact that more than one third of children (although there was no difference between DHCA and LF) were identified as requiring remedial academic services and that this may eventually be correlated with problems in executive function, such as organizing and implementing strategies and plans and modifying them as needed. Both groups are impaired compared with normal children, signifying that if this is related to CPB, our strategies need to improve. Although there are ample data (some of which are cited in these studies) to imply that long-term neurologic outcome may be related to underlying defects-as opposed to CPB strategy (eg, the presence of a ventricular septal defect, socioeconomic class of patients, the presence of preoperative hypoxemia, or the postoperative hemodynamic status), there is a disturbing reality that our CPB systems are still responsible for some of the outcome that can be measured in survivors of neonatal cardiac repair. We have an opportunity to improve. Data looking at cognitive outcome in adults after coronary artery bypass graft surgery and from children 
undergoing surgical versus catheterization laboratory closure of atrial septal defects imply that CPB itself may be a risk factor for neurologic outcome. ${ }^{47,48}$ Indeed, the Boston authors did not have a neonatal CPB control for their studies, and using non-CPB controls may not be appropriate in terms of arriving at conclusions regarding the effects of DHCA and LF. CPB may itself be a major factor in what happens over the long term to our patients, whether we choose to use DHCA or LF. Recent data from Galli and colleagues at Children's Hospital of Philadelphia indicate that application of CPB to neonates may be a risk factor for neurologic outcome. ${ }^{49}$ This study evaluated the incidence of cerebral white matter injury after neonatal and infant cardiac surgery. White matter injury was common in neonates $(>50 \%)$ but rare in older infants $(4 \%)$. Immaturity of the brain, particularly oligodendrocytes, may increase the risk of CPB-induced injury.

In addition, some patients may be at increased risk of injury secondary to genetic factors. Polymorphisms of apolipoprotein E (APOE) have been identified as a risk factor for worse neurologic recovery after a variety of central nervous system injuries. A recent single-institution prospective study of patients 6 months of age or younger undergoing CPB for repair of congenital heart disease demonstrated a significant association between $A P O E$ genotype and postoperative neurodevelopmental dysfunction. APOE $\epsilon 2$ allele carriers had significantly lower Psychomotor Development Index scores at 1 year of age after having cardiac surgery as infants. The effect is independent of ethnicity, socioeconomic status, cardiac defect, and use of DHCA. Thus, genetic polymorphisms that decrease neuroresiliency and impair neuronal repair after central nervous system injury are important risk factors for neurodevelopmental dysfunction after infant cardiac surgery and may be critical to neurodevelopmental outcome regardless of the CPB strategy used. ${ }^{49,50}$

Fortunately, as implied by the authors in the study on DHCA duration, ${ }^{1}$ our systems have improved. The findings described in both Boston studies ${ }^{1,2}$ were the result of historical CPB and DHCA strategies that have been significantly improved over the past decade. In a recent review by Menasché and colleagues, ${ }^{51}$ the observed incidence of objective manifestations of brain injury after operations in children (eg, seizures, movement disorders, or coma) have been substantially reduced compared with what was seen in the late 1980s and early 1990s - the time frame for patient enrollment in these 2 studies on DHCA versus LF. We can infer from this that $\mathrm{CPB}$ has become safer from a neurologic perspective. This is not an unrealistic inference. There have been numerous improvements in neonatal CPB in the past decade. ${ }^{52,53}$ Some of these have been related to advances in technology and some to research-driven changes in the way that DHCA and neonatal CPB are applied. With recognition and control of the inflammatory effects of CPB on neonates, their response to CPB has improved, and this has undoubtedly affected neurologic responses. ${ }^{54-57} \mathrm{We}$ can conjecture that on the basis of the ability to better harness the inflammatory effects of $\mathrm{CPB}$, neurologic outcome after exposure to LFCPB might be better than that described for the patients in the Boston Children's study. However, it is very likely that the outcome after exposure to DHCA is even better. For one thing, patients exposed to DHCA will benefit from the same advances in CPB that have evolved over the past decade. In addition, there have been numerous advances in the understanding of how to improve brain protection during exposure to DHCA. Restudying a cohort of patients in the modern era, with a protocol similar to that used in the Boston Children's transposition of the great arteries study, might actually demonstrate an advantage for DHCA if the strategy used currently recommended techniques.

Our current understanding of DHCA uses a variety of strategies, including using preoperative steroids ${ }^{54,58}$; recognizing high-risk groups ${ }^{35,52}$ (such as those with aortopulmonary collaterals or those who will have postoperative hypoxemia); providing adequate duration of pre-DHCA cooling, ${ }^{11,27}$ often with cooling to temperatures less than $18^{\circ} \mathrm{C}^{20,42}$; and using a pH-stat as opposed to alpha-stat blood gas strategy. ${ }^{18,20,36,40,42,59}$ Preoperative hyperoxygenation has been recommended for infants who will be exposed to longer durations of DHCA, ${ }^{60}$ and some recommend conversion to alpha-stat (after pH-stat) cooling just before DHCA ${ }^{40}$ Perhaps the most significant recommendation that can affect the outcome after DHCA, especially in light of the findings related to duration of DHCA and outcome, is to limit the exposure to DHCA to only those periods when it is necessary or to provide some form of cerebroplegia. Intermittent perfusion, between DHCA periods limited to 15 to 20 minutes, may virtually abolish the neurologic injury seen after exposure to DHCA. ${ }^{37}$ After DHCA, the use of modified ultrafiltration ${ }^{41}$ and, especially, protection of postoperative hemodynamics, including the use of extracorporeal life support (extracorporeal membrane oxygenation or ventricular assist device $)^{52}$ may be particularly beneficial in protecting the brain from injury. There is little question that the application of DHCA in 2004 is far safer and better understood than it was in the time frame that this study was conducted, and it may be that a repeat of the investigation would show very little difference from normal. In fact, preliminary data suggest this to be the case, even in a high-risk population such as those infants with hypoplastic left heart syndrome undergoing the Norwood procedure. $^{61}$

The authors also contend, from reviewing their outcomes in the article on duration of DHCA, ${ }^{1}$ that their "findings 
indicate that neurodevelopmental sequelae of DHCA are related to its duration in a nonlinear fashion." They base this contention on their outcomes versus "cut points." We urge caution with this interpretation. Ischemia causes a doserelated injury in almost any model that has been closely studied. In fact, metabolic studies of brain recovery after exposure to DHCA verified this phenomenon in a neonatal model exposed to varying durations of DHCA. ${ }^{38}$ It may be that it takes a threshold of injury to the brain before functional effects become apparent, but this does not mean that damage has not occurred. This underscores the very important limitation in any study of neurologic function after exposure to the systems we use for infant heart repair. Unlike our ability to study myocardial function, which is relatively easy to evaluate in terms of systolic and diastolic function, cerebral function is mired in complexity. There are so many functions to the brain-motor, sensory, cognitive, and so on-that the authors had to use a plethora of tests to uncover the effects of CPB strategies, and it is still not possible to distinguish the effects of DHCA or LFCPB from all the other elements that might affect long-term brain function.

What we can say is that we need to respect the enormous physiologic extremes that our infant patients are exposed to during our attempts to repair their heart defects. Although armchair reasoning might lead us to assume that continuous LF would be superior to DHCA, the data do not support this-neither the data from animal research laboratories nor the data provided in this, the best available, outcome study of neurodevelopmental outcomes for our infant patients. We also have to be careful not to use the outcome data from these studies to support complacency. Both groups studied were impaired. We can and should improve. Perhaps we already have. DHCA probably causes a dose-related ischemic injury to the brain that can be attenuated by numerous contemporary strategies and that can be virtually eliminated by periodic cerebral reperfusion to limit the ischemic insult. LFCPB extends the inflammatory effects of CPB on the brain, and this may counter the predicted advantage of avoiding ischemia. It is likely that we will learn better methods of diminishing this problem in the years ahead. Current work with miniaturized circuitry that avoids the need for blood transfusion in neonatal animals shows substantial promise in this arena. The updated Boston circulatory arrest studies recently published in the Journal ${ }^{1,2}$ neither support nor reject the use of either DHCA or LFCPB as a preferred strategy for infant heart repair. This is an emotionally charged issue for some centers, but the reality is that in 2004, there is ample evidence to support the use of either strategy and optimism that continued investigation will help us further refine neonatal CPB so that outcomes will get even better in the future.

\section{References}

1. Wypij D, Newburger JW, Rappaport LA, du Plessis AJ, Jonas RA, Wernovsky G, et al. The effect of duration of deep hypothermic circulatory arrest in infant heart surgery on late neurodevelopment: the Boston Circulatory Arrest Trial. J Thorac Cardiovasc Surg. 2003;126: 1397-403.

2. Bellinger DC, Wypij D, du Plessis AJ, Rappaport LA, Jonas RA, Wernovsky G, et al. Neurodevelopmental status at eight years in children with dextro-transposition of the great arteries: the Boston Circulatory Arrest Trial. J Thorac Cardiovasc Surg. 2003;126:138596.

3. Kirklin JW, Dawson B, Devloo RA, Theye RA. Open intracardiac operations: use of circulatory arrest during hypothermia induced by blood cooling. Ann Surg. 1961;154:769-74.

4. Barratt-Boyes BG, Simpson MM, Neutze JM. Intracardiac surgery in neonates and infants using deep hypothermia. Circulation. 1970;62: III73.

5. Kirklin JW, Barratt-Boyes BG. Cardiac surgery. 2nd ed. New York: Churchill Livingstone; 1993.

6. Ferry PC. Neurologic sequelae of cardiac surgery in children. Am J Dis Child. 1987;141:309-12.

7. Brunberg JA, Reilly EL, Doty DB. Central nervous system consequences in infants of cardiac surgery using deep hypothermia and circulatory arrest. Circulation. 1974;50(2 suppl):II60-9.

8. Weiss M, Weiss J, Cotton J, Nicolas F, Binet JP. A study of the electroencephalogram during surgery with deep hypothermia and circulatory arrest in infants. J Thorac Cardiovasc Surg. 1975;70: 316-29.

9. Wells FC, Coghill S, Caplan HL, Lincoln C. Duration of circulatory arrest does influence the psychological development of children after cardiac operation in early life. J Thorac Cardiovasc Surg. 1983;86: 823-831.

10. Barratt-Boyes BG. Choreoathetosis as a complication of cardiopulmonary bypass. Ann Thorac Surg. 1990;50:693-4.

11. Bellinger DC, Wernovsky G, Rappaport LA, Lang P, Hickey PR, Jonas RA, et al. Rapid cooling of infants on cardiopulmonary bypass adversely affects later cognitive function [abstract]. Circulation. 1988; 78:A358.

12. Bellinger DC, Jonas RA, Rappaport LA, Wypij D, Wernobsky G, Kuban KCK, et al. Developmental and neurologic status of children after heart surgery with hypothermic circulatory arrest or low-flow cardiopulmonary bypass. N Engl J Med. 1995;332:549-55.

13. Brunberg JA, Doty DB, Reilly EL. Choreoathetosis in infants following cardiac surgery with deep hypothermia and circulatory arrest. J Pediatr. 1974;84:232-5.

14. Clarkson PM, Barton MB, MacArthur A, Barratt-Boyes BG, Whitlock RM, Neutze JM. Developmental progress after cardiac surgery in infancy using hypothermia and circulatory arrest. Circulation. 1980; 62:855-61.

15. Ferry PC. Neurologic sequelae of open-heart surgery in children. An 'irritating question'. Am J Dis Child. 1990;144:369-73.

16. Fessatidis IT, Thomas VL, Shore DF, Sedgwick ME, Hunt RH, Weller RO. Brain damage after profoundly hypothermic circulatory arrest: correlations between neurophysiologic and neuropathologic findings. An experimental study in vertebrates. J Thorac Cardiovasc Surg. 1993;106:32-41.

17. Robinson RO, Samuels M, Pohl KRE. Choreic syndrome after cardiac surgery. Arch Dis Child. 1988;63:1466-9.

18. Aoki M, Nomura F, Stromski ME, Jonas RA. Effects of $\mathrm{pH}$ on brain energetics after hypothermic circulatory arrest. Ann Thorac Surg. 1993;55:1093-2103.

19. du Plessis AJ, Treves ST, Hickey PR, O’Tuama L, Barlow CF, Costello J, et al. Regional cerebral perfusion abnormalities after cardiac operations: single photon emission computed tomography (SPECT) findings in children with postoperative movement disorders. J Thorac Cardiovasc Surg. 1994;107:1036-43.

20. Gillinov AM, Redmond JM, Zehr KJ, Troncoso JC, Arroyo S, Lesser RP, et al. Superior cerebral protection with profound hypothermia during circulatory arrest. Ann Thorac Surg. 1993;55: 1432-9.

21. Greeley WJ, Ungerleider RM, Smith LR, Reves JR. Cardiopulmonary 
bypass alters cerebral blood flow in infants and children during and after cardiovascular surgery. Circulation. 1988;78:II356-63.

22. Greeley WJ, Ungerleider RM, Smith LR, Reves JG. The effects of deep hypothermic cardiopulmonary bypass and total circulatory arrest on cerebral blood flow in infants and children. $J$ Thorac Cardiovasc Surg. 1989;97:737-45.

23. Greeley WJ, Ungerleider RM, Kern FH, Brusino FG, Smith LR, Reves JG. Effects of cardiopulmonary bypass on cerebral blood flow in neonates, infants, and children. Circulation. 1989;80:1209-15.

24. Greeley WJ, Kern FH, Ungerleider RM, Boyd JL III, Quill T, Smith LR, et al. The effect of hypothermic cardiopulmonary bypass and total circulatory arrest on cerebral metabolism in neonates, infants, and children. J Thorac Cardiovasc Surg. 1991;101:783-94.

25. Greeley WJ, Bracey VA, Ungerleider RM, Greibel JA, Kern FH, Reves JG, et al. Recovery of cerebral metabolism and mitochondrial oxidation state is delayed after hypothermic circulatory arrest. Circulation. 1991;84(suppl 3):400-15.

26. Greeley WJ, Bracey VA, Ungerleider RM, Greibel JA, Kern FH, Reves JG, et al. Recovery of cerebral metabolism and mitochondrial oxidation state are delayed after hypothermic circulatory arrest. Circulation. 1991;84(5 suppl):III400-6.

27. Greeley WJ, Kern FH, Meliones JN, Ungerleider RM. Effect of deep hypothermia and circulatory arrest on cerebral blood flow and metabolism. Ann Thorac Surg. 1993;56:1464-6.

28. Greeley WJ, Kern FH, Mault JR, Skaryak LA, Ungerleider RM Mechanisms of injury and methods of protection of the brain during cardiac surgery in neonates and infants. Cardiol Young. 1993;3:31730 .

29. Hillier SC, Burrows FA, Bissonnette B, Taylor RH. Cerebral hemodynamics in neonates and infants undergoing cardiopulmonary bypass and profound hypothermic circulatory arrest: assessment by transcranial Doppler sonography. Anesth Analg. 1991;72:723-8.

30. Jonas RA, Bellinger DC, Rappaport LA, Wernovsky G, Hickey PR, Farrell DM, et al. Relation of pH strategy and developmental outcome after hypothermic circulatory arrest. J Thorac Cardiovasc Surg. 1993; 106:362-8.

31. Kawata H, Fackler JC, Aoki M, Jonas RA. Recovery of cerebral blood flow and energy state after hypothermic circulatory arrest versus low flow bypass in piglets. $J$ Thorac Cardiovasc Surg. 1993;106:671-85.

32. Kern FH, Ungerleider RM, Quill TJ, Baldwin B, White WD, Reves JG, et al. Cerebral blood flow response to changes in arterial carbon dioxide tension during hypothermic cardiopulmonary bypass in children. J Thorac Cardiovasc Surg. 1991;101:618-22.

33. Kern FH, Jonas RA, Mayer JE Jr, Hanley FL, Castaneda AR, Hickey PR. Temperature monitoring during CPB in infants: does it predict efficient brain cooling? Ann Thorac Surg. 1992;54:749-54.

34. Kern FH, Ungerleider RM, Schulman SR, Meliones JN, Schell RM, Baldwin B, et al. Comparison of two strategies of cardiopulmonary bypass cooling on jugular venous oxygen saturation in neonates and infants. Ann Thorac Surg. 1995;60:1198-202.

35. Kirshbom PM, Skaryak LA, DiBerardo LR, Kern FH, Greeley WJ, Gaynor JW, et al. Effect of aortopulmonary collaterals on cerebral cooling and metabolic recovery during cardiopulmonary bypass and circulatory arrest. Circulation. 1995;92(suppl 2):II490-4.

36. Kirshbom PM, Skaryak LA, DiBernardo LR, Kern FH, Greeley WJ, Gaynor JW, et al. pH-Stat cooling improves cerebral metabolic recovery after circulatory arrest in a piglet model of aorto-pulmonary collaterals. J Thorac Cardiovasc Surg. 1996;111:147-57.

37. Langley S, Chai PJ, Miller SE, Mault JR, Jaggers J, Tusi SS, et al. Intermittent perfusion protects the brain during deep hypothermic circulatory arrest. Ann Thorac Surg. 1999;68:4-13.

38. Mault JR, Ohtake S, Klingensmith ME, Heinle JS, Greeley WJ, Ungerleider RM. Cerebral metabolism and circulatory arrest: effects of duration and strategies for protection. Ann Thorac Surg. 1993;55:5764.

39. Mault JR, Whitaker EG, Heinle JS, Lodge AJ, Greeley WJ, Ungerleider RM. Cerebral metabolic effects of sequential periods of hypothermic circulatory arrest. Ann Thorac Surg. 1994;57:96-101.

40. Skaryak LA, Kirshbom PM, DiBernardo LR, Kern FH, Greeley WJ, Gaynor JW, et al. Low flow bypass versus circulatory arrest: similar vulnerability to postbypass cerebral metabolic injury. Surg Forum. 1994;45:258-9.

41. Skaryak LA, Kirshbom PM, DiBernardo LR, Kern FH, Greeley WJ, Ungerleider RM, et al. Modified ultrafiltration improves cerebral metabolic recovery after circulatory arrest. J Thorac Cardiovasc Surg. 1995; 109:744-52.

42. Skaryak LA, Chai PJ, Kern FH, Greeley WJ, Ungerleider RM. Blood gas management and degree of cooling: effects on cerebral metabolism before and after circulatory arrest. J Thorac Cardiovasc Surg. 1995; 110:1649-57.

43. Watanabe T, Miura M, Orita H, Kobayasi M, Washio M. Brain tissue $\mathrm{pH}$, oxygen tension, and carbon dioxide tension in profoundly hypothermic cardiopulmonary bypass. J Thorac Cardiovasc Surg. 1990; 100:274-80

44. Hindman BJ, Dexter F, Cutkomp J, Smith T, Todd MM, Tinker JH. Brain blood flow and metabolism do not decrease at stable brain temperature during cardiopulmonary bypass in rabbits. Anesthesiology. 1992;77:342-51.

45. Pigula FA, Nemoto EM, Griffith BP, Siewers RD. Regional lowflow perfusion provides cerebral circulatory support during neonatal aortic arch reconstruction. J Thorac Cardiovasc Surg. 2000;119: 331-9.

46. Hanley F. Discussion of Pigula, et al. Regional low-flow perfusion provides cerebral circulatory support during neonatal aortic arch reconstruction. J Thorac Cardiovasc Surg. 2000;119:337-8.

47. Visconti KJ, Bichell DP, Jonas RA, Newburger JW, Bellinger DC. Developmental outcome after surgical versus interventional closure of secundum atrial septal defect in children. Circulation. 1999;100(19 suppl):II145-50.

48. Newman MF, Kirchner JL, Phillips-Bute B, Gaver V, Grocott H, Jones RH, et al. Longitudinal assessment of neurocognitive function after coronary-artery bypass surgery. $N$ Engl J Med. 2001;344: 395-402.

49. Galli KK, Zimmerman RA, Jarvik GP, Wernovsky G, Kuypers MK, Clancy RR, et al. Periventricular leukomalacia is common following neonatal cardiac surgery. J Thorac Cardiovasc Surg. 2004;127:692704 .

50. Gaynor JW, Gerdes M, Zackai EH, Bernbaum J, Wernovsky G, Clancy RR, et al. Apolipoprotein E genotype and neurodevelopmental sequelae of infant cardiac surgery. J Thorac Cardiovasc Surg. 2003; 126:1736-45.

51. Menasché CC, du Plessis AJ, Wessel DL, Jonas RA, Newburger JW. Current incidence of acute neurological complications after open-heart operations in children. Ann Thorac Surg. 2002;73:1752-8.

52. Shen I, Giacomuzzi C, Ungerleider RM. Current strategies for optimizing the use of cardiopulmonary bypass in neonates and infants. Ann Thorac Surg. 2003;75:S729-34.

53. Jaggers JJ, Shearer I, Ungerleider RM. Cardiopulmonary bypass in infants and children. In: Gravlee GP, Davis RF, Kurusz M, Utley JR, editors. Cardiopulmonary bypass: principles and practice. Philadelphia: Lippincott, Williams \& Wilkins; 2000. p. 633-61.

54. Langley SM, Chai PJ, Jaggers JJ, Ungerleider RM. Preoperative high dose methylprednisolone attenuates the cerebral response to deep hypothermic circulatory arrest. Eur J Cardiothorac Surg. 2000;17: 279-86.

55. Langley SM, Chai PJ, Jaggers JJ, Ungerleider RM. The effects of a leukocyte depleting filter on cerebral and renal recovery following deep hypothermic circulatory arrest. J Thorac Cardiovasc Surg. 2000; 119:1262-9.

56. Scheller MS, Branson PJ, Cornacchia LG, Alksne JF. A comparison of the effects on neuronal Golgi morphology, assessed with electron microscopy, of cardiopulmonary bypass, low-flow bypass, and circulatory arrest during profound hypothermia. J Thorac Cardiovasc Surg. 1992;104:1396-404.

57. Westaby S, Saatvedt K, White S, Katsumata T, van Oeveren W, Halligan $\mathrm{P}$. Is there a relationship between cognitive dysfunction and systemic inflammatory response after cardiopulmonary bypass? Ann Thorac Surg. 2001;71:667-72.

58. Lodge AJ, Chai PJ, Daggett CW, Ungerleider RM, Jaggers J. Methylprednisolone reduces the inflammatory response to cardiopulmonary 
bypass in neonatal piglets: timing of dose is important. $J$ Thorac Cardiovasc Surg. 1999;117:515-22.

59. Jonas RA, Bellinger DC, Rappaport LA, Newburger JW. Relation of $\mathrm{pH}$ strategy and developmental outcome after hypothermic circulatory arrest. J Thorac Cardiovasc Surg. 1993;106:362-8.

60. Pearl JM, Thomaas DW, Grist G, Duffy JY, Manning PB. Hyperoxia for management of acid-base status during deep hypothermia with circulatory arrest. Ann Thorac Surg. 2000;70:751-5.

61. Ungerleider RM, Shen I, Schultz J, Giacomuzzi C, Heller E, Farrel D, et al. Routine mechanical ventricular assist following the Norwood procedure-improved neurologic outcome and excellent hospital survival. Ann Thorac Surg. 2004;77:18-22.

\section{JTCVS On-Line Manuscript Submission and Review}

Please visit http://www.editorialmanager.com/jtcvs/

Effective September 15, 2001, authors and reviewers may submit manuscripts and reviews electronically via Editorial Manager, our new Web-based system with full electronic submission, review, and status update capabilities.

As we move from paper to electronic submissions, the Editorial Office will make proxy submissions of all manuscripts accompanied by a diskette containing the electronic files of the text, tables, and figures. Editors, authors, and reviewers will receive automatic e-mails when significant events occur.

We strongly encourage all authors and reviewers to use Editorial Manager. Although we will continue to accommodate the submission of paper manuscripts for some months, our goal is to be completely electronic within 9 to 12 months.

All individuals currently in our database for whom we have e-mail addresses will receive via e-mail a system-assigned username and password that can be used to log in to the system without prior registration. All those not receiving the e-mail must register the first time they use the system.

As with any broad systemic change, the conversion to the new system will take some time to complete. We ask your patience as we replace our in-office database with the new system. We also encourage you to take advantage of the speed and efficiency that the new system will provide for us all: editor, author, reviewer, and publisher. 